\title{
Akkiz punktum stenozunda tanı, etyoloji ve tedavi seçenekleri
}

\author{
Diagnosis, etiology and treatment options in acquired punctal stenosis
}

Hatice Deniz İlhan

Özet

Punktum stenozu, önemli bir epifora nedenidir. Konjenital olabilse de daha çok akkiz görülen, kanalikülün eksternal açıklığının daralmasıdır. Punktum açıklığı, tam tıkanıklığa kadar farkı genişliklerde ve şekillerde görülebilir. İdiyopatik ve involüsyonel başta olmak üzere kronik enflamatuvar sürece yol açan lokal ve sistemik enflamatuvar hastalıklar, kapak malformasyonları, topikal ve sistemik ilaç kullanımı ve enfeksiyonlara bağlı olarak punktum stenozu gelişmektedir. Punktum stenozunun tedavisinde, kanalikülün proksimali ve eksternal açıklığın genişletilmesine yönelik Snip ampulloplasti, Panç ampulloplasti ve genişliğin devamının sağlanması amacıyla delikli punktum tıkaçları, stent kullanımları gibi etkili olduğu gösterilen minimal cerrahi yöntemler uygulanmaktadır. Hastaların önemli bölümü başarılı bir şekilde tedavi edilse de, bazı hastalarda punktum stenozunun tekrarladığı görülmektedir. Akkiz punktum stenozunun nedenlerinin, klinik yaklaşım ve tedavi seçeneklerinin bilinmesi bu patoloji nedenli epiforanın tedavisinde başarı için gereklidir.

Anahtar kelimeler: Punktum stenozu, epifora, etyoloji, tedavi.

İlhan HD. Akkiz punktum stenozunda tanı, etyoloji ve tedavi seçenekleri. Pam Tıp Derg 2021;14:289-297.

\begin{abstract}
Punctal stenosis is an important cause of epiphora. Although it might be seen congenital, it is mostly acquired stenosis seen in adults. Punctum has different shapes and also measurements. Punctum can be in different degrees of stenosis. Punctal stenosis is mainly found idiopathic and involutional but it can also develop due to local and systemic inflammatory diseases, eyelid malformations, topical or systemic medication side effects and infections leading to chronic inflammatory process. In the treatment of punctal stenosis, minimal surgical methods such as Snip ampulloplasty, Punch ampulloplasty for widening of the external opening of punctum and proximal canalliculus and several stents usages in order to continue the patency are performed. Although most patients are successfully treated, punctal stenosis recurs in a group of patients. Careful examination of the patient with epiphora, the knowledge of its etiology, clinical approaches and treatment options is essential for success in the treatment of punctal stenosis.
\end{abstract}

Key words: Punctal stenosis, epiphora, etiology, treatment.

Ilhan HD. Diagnosis, etiology and treatment options in acquired punctal stenosis. Pam Med J 2021;14:289-297.

\section{Giriş}

Epifora, karmaşık birçok faktör nedeniyle gözyaşı drenaj sisteminin bozulması sonucu ortaya çıkar. Punktum stenozu (PS), tek başına veya diğer nedenlerle kombine görülebilen epiforanın önemli bir nedenidir [1, 2]. PS konjenital (Resim 1) ya da akkiz olabilir. Konjenital olgularda tam oklüzyon punktal agenezi olarak tanımlanır. Akkiz görülen PS ise lakrimal kanalikülün eksternal açıklığının sonradan epiforaya yol açarak pek çok nedenle gelişen stenozudur. Kesin insidansı belirlenemese de tahmini insidans, genel popülasyonda \%17,3 olarak kaydedilmiştir [1]. Oküloplasti kliniklerine epifora nedeniyle sevk edilen hastalara dayalı çalışmalarda ise insidans değişkenlik gösterir $(\% 8-\% 37,8)[2,3]$. Altmış beş yaş üstü popülasyonda prevalansın daha yüksek olduğu görülmektedir $(\% 63,32)$ [4]. Bu derlemede akkiz PS'nun nedenleri, klinik yaklaşım ve tedavi seçenekleri incelenecektir. 


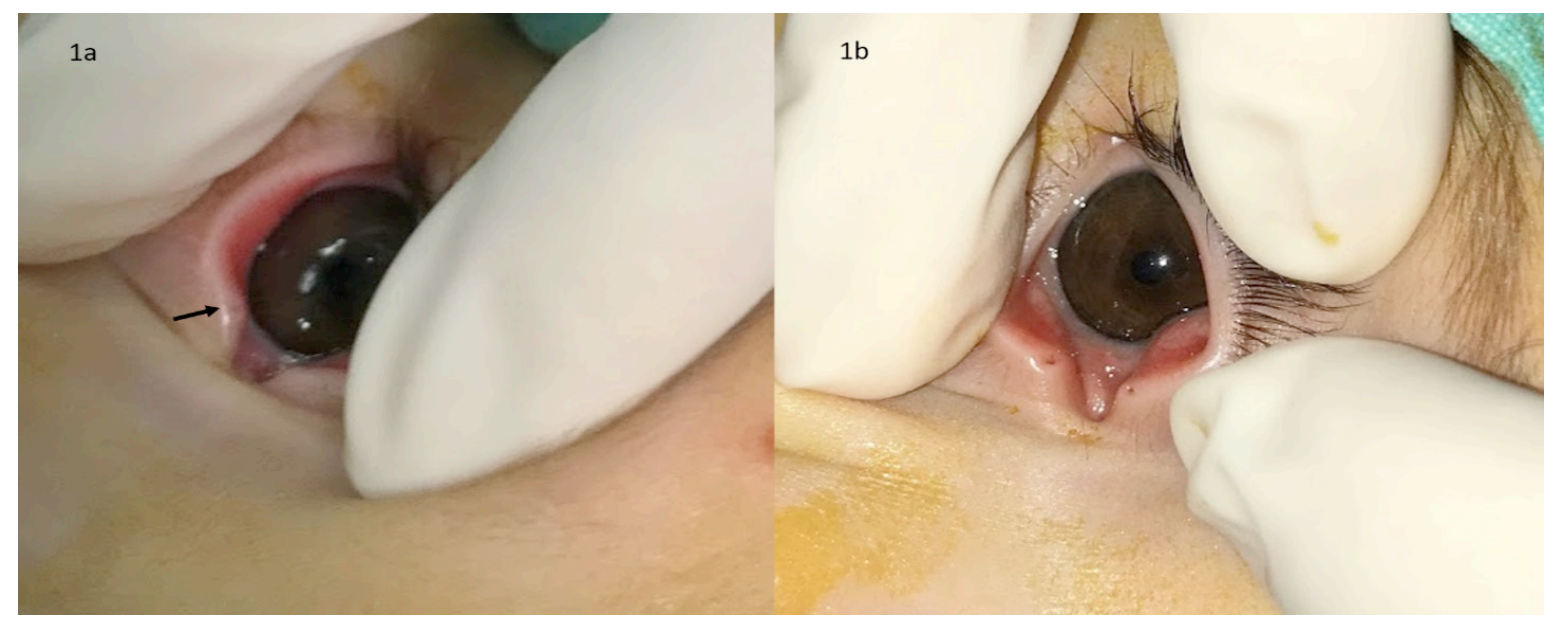

Resim 1. Sağ epiforası olan bebekte 1a'da alt ve üst punktumun dar nokta şeklinde olup bir membran ile kaplı olduğu (siyah ok) izlendi. Punktum dilatatörü ile genişletildikten sonra açıklık sağlandı (1b)

\section{Tanım, Epidemiyoloji}

Klinik olarak epifora ile punktum şekil ve boyutukonusundarandomizekontrollüprospektif karşılaştırmalı bir çalışma bulunmamaktadır. $\mathrm{Bu}$ nedenle punktum genişliğinin hangi değerin altında epifora geliştirdiği konusu net değildir. Hangi punktal darlıkta tedavi gerekliliği konusunda da fikir birliği bulunmamaktadır.

Gözyaşı drenaj sisteminin başlangıcını oluşturan punktumlar alt ve üst göz kapaklarının iç kısmında, tarsal plağın yapısı dahilinde medialde bulunur [5]. Punktum, fibröz bir halka ile çevrilidir ve plika semilunaris ve karinkülün oluşturduğu gözyaşı gölüne açılır. Riolan kası ve medial kapak kenarındaki yoğun fibröz doku punktum ve ampullaya tutunur. Her iki yapı punktumu medial ve posteriora çeker [6]. Biyomikroskobik incelemede farklı punktum şekilleri (kapalı, yuvarlak, oval ve yarık) ile karşılaşılır [7]. En sık karşılaşılan punktum şekli yuvarlak olup $(\% 55,6)$, cinsiyetler arasında punktum şekilleri açısından fark bulunmamıştır. Punktum genişliği, sağlıklı erişkin bireylerde beyaz Irkta ortalama 0,32 $\pm 0,16 \mathrm{~mm}^{2}$ dir [8]. Asyalılarda ise punktumlar daha dar kaydedilmiştir $\left(0,15 \pm 0,08 \mathrm{~mm}^{2}\right)$ [9]. Alt punktum üst punktumdan $\left(0,1-0,7 \mathrm{~mm}^{2}\right)$ daha geniş bulunurken, sağ ve sol punktum ölçümleri benzer bulunmuştur [8]. Patel [7] ise yuvarlak punktumların iç genişliğinin $0,10 \pm 0,07 \mathrm{~mm}$ olduğunu tespit etmiştir. Bukhari [2], genel oftalmoloji polikliniğine başvuranlarda PS'nun $\% 54,3$ oranında ve üst punktumda daha fazla olduğunu bildirirken, Kashkouli ve ark. [10] ise PS tanısı almış hastaların sadece \%10,3'ünde üst punktumda stenoz bildirmiştir. Kadınerkek arasında sağlıklı bireylerde punktal ölçümler benzer olsa da punktum stenozu \%63-70 oranında kadınlarda görülmektedir [1, 10, 11]. Ancak cinsiyet farkının olmadığını gösteren çalışmalar da vardır [2, 8]. Yaş arttıkça kadınlarda görülme sıklığı da artmaktadır [1]. Bu durum, menopoz sonrası hormonal değişikliklerin stenozda bir faktör olabileceğini düşündürmektedir.

\section{Etyoloji}

Edinsel PS yaygın olarak involüsyonel ve idiopatik görülse de birçok faktöre sekonder gelişebilmektedir. Etyopatogenezde sorumlu tutulan faktörlerin başında yaşlanma ile gelişen involüsyonel değişiklikler gelmektedir $[8,10$, 12]. Yaşlanma ile dokulardaki atrofi, yoğun fibröz yapının esnemesine ve etrafını saran Horner kas liflerinin atonisine; bu da PS'na yol açmaktadır [12]. PS tanısı alan kişilerin yaş ortalaması 60'ın üzerindedir [2, 4, 8, 10].

Lokal kronik inflamasyon PS gelişiminden sorumlu tutulmaktadır. Port ve ark. [13] patoloji örnekleri sınırı sayıda olsa da, punktoplasti yapılmış hastaların punktum örneklerinde $\% 83,3$ oranında kronik inflamatuar değişiklikler ve/veya fibrozis saptamışlardır. Lokal enflamasyonlar içinde kronik blefarit, edinsel PS'nun tanımlanmış bir nedenidir [2, 10]. Öte yandan, Viso ve ark. [1] kronik blefariti punktum stenozu ile ilişkilendirmemiştir. Lokal enflamasyonun eşlik ettiği kuru göz, punktum stenozu ile birlikte sık görülmektedir (Resim 2) [2]. Her iki durumun da yaş ile artışı ayırıcı tanı ve tedavide önemlidir. Kronik irritasyonun yol açtı̆̆ı enflamasyonun 
görüldüğü diğer bir patoloji kapak malpozisyonlarıdır. Medial veya total ektropiyon punktum çevresinde enflamasyon ve kuruluğa yol açarak sekonder PS'na yol açmaktadır (Resim 3) [14]. Bu hastalarda nedene yönelik tedavi malpozisyonun giderilmesi, stenozun şiddetine göre malpozisyon cerrahisi sırasında tedavisi yeterli olacaktır [15].

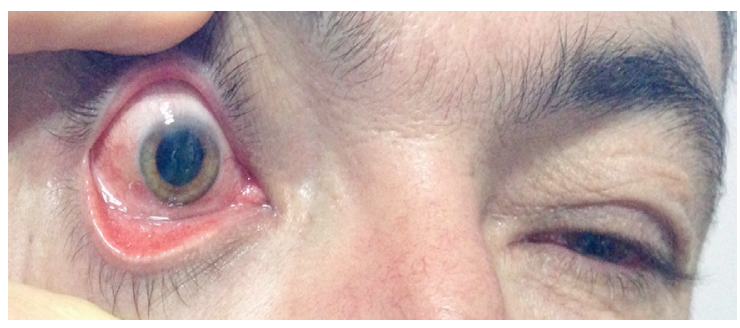

Resim 2. Akne rozesea tanılı kronik oküler yüzey enflamasyonu, kronik posterior blefaritli hastanın punktum açıklığı hiç görülmüyor

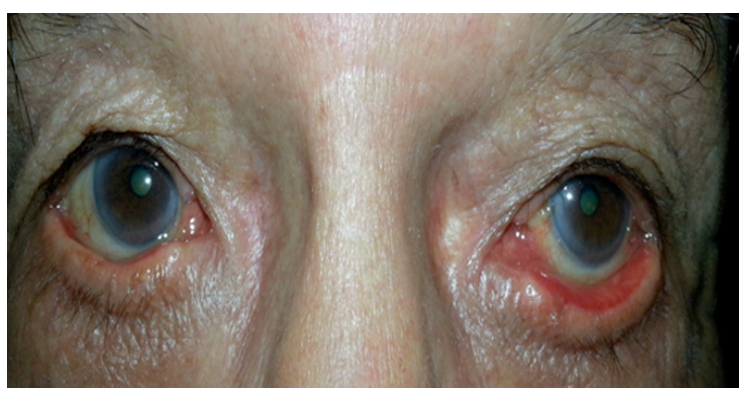

Resim 3. Ektropiyonlu hastanın alt punktumlarının bilateral dar olduğu izleniyor

Oküler enflamasyonun eşlik ettiği Stevens Johnson Sendromu, oküler skatrisyel pemfigoid, graft versus host hastalığı gibi immün mekanizmaların rol aldıkları sistemik enflamatuvar olaylarda da punktum stenozu görülmektedir [16-18]. Bu hastalarda ağır kuru göz olması nedeniyle stenoza yönelik bir cerrahi çoğunlukla gerekmemektedir. Cilt ve mukozaları tutan otoimmün hastalıklardan liken planusta da oküler yüzey ile birlikte punktum ve lakrimal drenaj sisteminde fibrozis ve stenoz olabilmektedir [16]. Sistemik hastalıklardan acrodermatitis enteropathica ve porfiria cutanea tardada da PS geliştiği bildirilmiştir [19].

Trahom ve herpes simpleks gibi göz kapağını etkileyen enfeksiyonlar PS'na neden olabilir [19]. Klamidya, aktinomiçes ve HPV de bildirilen diğer patojenlerdir [19].

Nadir de olsa peripunktal bölgede gelişen tümörlerde PS gelişebilir (Resim 4) [20]. Lokal radyoterapi uygulaması da PS nedenleri arasındadır [19]. Sekonder iyileşmeye bırakılmış kanalikül ile birlikte punktumun etkilendiği kapak travmalarında da PS görülmektedir [19].

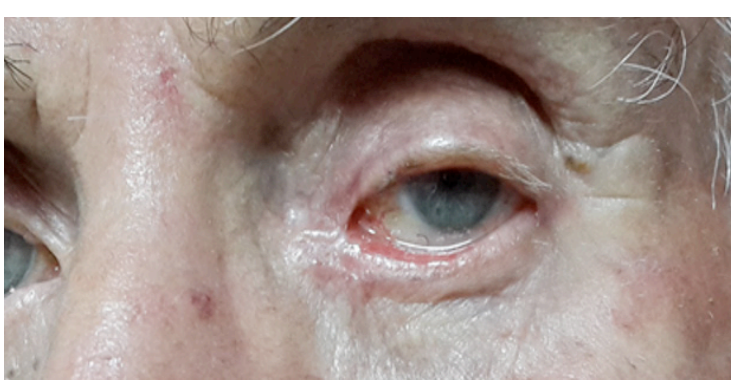

Resim 4. Sol göz medialinde bazal hücreli karsinom, punktumların stenozu ve ektropiyona yol açmaktadır

Diğer bir etken de topikal veya sistemik kullanılan ilaçlardır. Uzun süre topikal damlalar PS'nun nedeni olabilmektedir. Birçok topikal antiglokomatöz ilaç ile PS ilişkilendirilmiştir [21]. Tobramisin, deksametazon, tropikamid, kloramfenikol, prednizolon asetat, fenilefrin, nafazolin, florometolon, indometazin, propinem ve dipivefrin gibi pek çok topikal damla ile PS gelişen olgular da bildirilmiştir [21]. MitomisinC'nin PS'na neden olması tartışmalıdır. PS oluşturduğunu bildiren yayınlar olduğu gibi, PS tedavisinde cerrahi sırasında mitomisinC'nin kullanılmasının başarıyı arttırdığı da savunulmaktadır $[22,23]$. Öte yandan, mitomisinC'nin glokom cerrahisinde skleral yatağa uygulanmasının PS'nda ek bir artış yaratmadığı gösterilmiştir [24]. PS'nun, 5-florourasil ve dosetaksel gibi sistemik kemoterapötik ajanların kullanımında da geliştiği bildirilmiştir [25, 26]. Tiroid karsinomunun tedavisi için kullanılan radyoaktif iyot (I-131) kullanımı da PS nedenleri arasındadır [27].

PS'nun önemli bir oranı idiopatik gelişir [10]. Bu hastaların bir kısmında idiopatik ödematöz punktum stenozu (İÖPS) vardır (Resim 5). İÖPS'nda punktum çevresi ödemli ve hiperemiktir. $\mathrm{Bu}$ hastalarda öncelikli tedavi cerrahi değildir ve enflamasyonun baskılanmasına çalışılır. Hastaların üçte biri tedaviye cevap vermez [28].

Tekrarlayan punktum dilatasyonu ve nazolakrimal lavaj uygulamaları da iyatrojenik olarak PS gelişimine neden olabilir [11]. 


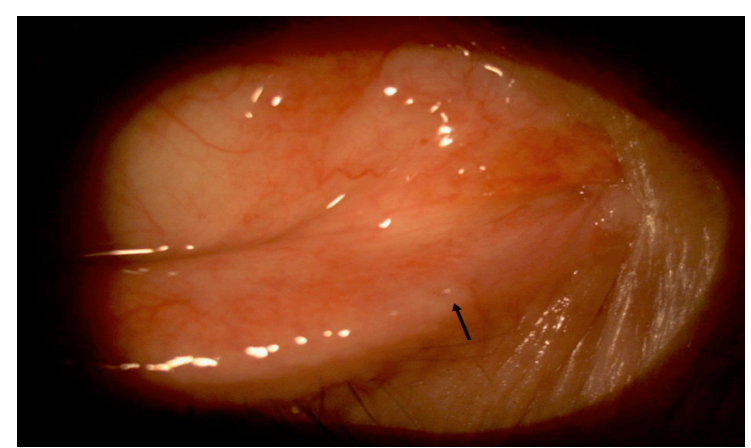

Resim 5. İdiyopatik ödematöz punktum stenozu olan hastanın sağ gözünde konjonktiva, alt punktum ve çevresi hiperemik, punktum ödemli ve açıklığı ödeme bağlı daralmış (siyah ok) izleniyor

\section{Hasta değerlendirmesi}

Epiforası olan bir hastada lakrimal drenaj sistemi dışındaki epifora nedenleri (kapak malpozisyonları, refleks gözyaşı üretimine bağlı olarak kuru göz ve oküler yüzeyin enflamatuar hastalıkları) ayırıcı tanıda düşünülmelidir. Sibley ve ark. [29], epifora nedeni olarak kısmi veya tam lakrimal sistem obstrüksiyonunu \%31,8 oranında belirtirken, hastaların \%28,7'sinde birden fazla neden bulmuşlardır. Bu çalışmada sekonder refleks gözyaşı üretimi $(\% 29,2)$ ve göz kapağı malpozisyonları $(\% 10,4)$ diğer faktörlerdir. Dikkatli bir inspeksiyon ile ektropion olup olmadığına bakılmalı, alt kapak gevşekliği distraksiyon testi ile, medial kantal ligaman gevşekliği horizontal kapak germe testi ile kontrol edilmelidir. Bazen sadece punktum ektropiyonu epifora nedeni olabilir. Oküler yüzeyde enflamasyon, kuru göz bulgularının varlığı incelenmelidir.

Normal bireylerde gözyaşı menisküs

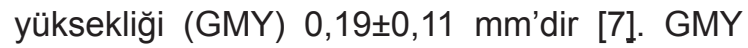
$0,2 \mathrm{~mm}$ 'nin üzerinde epifora semptomları ortaya çıkmaya başlar. Gözyaşı kaybolma zamanı \%2'lik fluorescein damlatıldıktan $5 \mathrm{dk}$. sonra bakılarak GYM'nin arttığı gösterilebilir. GMY'ndeki artış ve belirgin epifora olmasının dışında PS olan hastalarda rahatsızlık hissi de olabilir. Blefarit ve kuru göz varlığında da sulanma, rahatsızlık hissi olmakta, PS ile birlikte görülebilmektedir. $\mathrm{Bu}$ hastalarda öncelikle kuru göz ve/veya blefarit tedavisi yapılmalıdır. Refleks gözyaşı üretimi suni gözyaşı tedavisi ile geriledikten, blefarit varlığında blefarit tedavisi yapıldıktan sonra organik olarak bulunan PS değerlendirilmelidir. Kuru göz ve blefaritin tedavisi ile hastanın semptomları gerileyebilir. Hatta, varolan kuru gözün şiddetine bağlı olarak PS faydalı bile olabilir.

Punktum muayenesi biyomikroskobik inceleme ile yapılır. Punktum açıkığının genişliği Kashkuli ve ark.'nın [10] belirttiği gibi 0-5 arasında derecelendirilebilir (Tablo 1). Normal genişlikteki punktumdan 00-Bowman sondası rahatlıkla geçebilir. Eğer 26G lakrimal kanül veya 00-Bowman sondası dilatasyon gerekmeden punktumdan geçemiyorsa PS olarak tanımlanabilir.

Tablo 1. Kashkouli'ye [10] göre punktum stenozunun derecelendirilmesi

\begin{tabular}{ll}
\hline Derece & Punktum açıklığı \\
\hline 0 & Punktum seçilmiyor (punktal atrezi) \\
1 & Punktum zor görülür, bir zar veya fibröz yapı ile kaplı veya değil \\
2 & Normal boyuttan küçük ama tanınabilir \\
3 & Normal - 00 bowman sondası girebilir \\
4 & Küçük yarık $(<2 \mathrm{~mm})$, normalden büyük \\
5 & Büyük yarık $(>2 \mathrm{~mm})$, normalden büyük \\
\hline
\end{tabular}


PS'na kanalikül stenozu (KS) ve/veya ortak kanalikül stenozu (OKS) eşlik edebilir. Sekresyon, akut dakriyosistit bulguları, kanalikülit akılda tutulmalıdır. Bowman telleri ile KS olup olmadığı değerlendirilmelidir. Nazolakrimal lavaj yapılarak nazolakrimal kese ve kanal açıklığı kontrol edilmelidir. Bir çalışmalarında Kashkouli ve ark. [14], PS'lu hastalarının sadece \%39,6'sında kanalikülün sağlıklı olduğunu kaydetmişlerdir.

Epifora sadece PS'na bağlı değilse, tedavide diğer nedenlere yönelik medikal ve cerrahi seçenekler de düşünülmelidir.

\section{Tedavi}

PS tedavisinde temel prensip, yeterli bir açıklık yaratarak, gözyaşı gölüne karşı punktal pozisyonun korunması, punktal açıklığa gözyaşı erişiminin artırılması ve lakrimal pompanın işlevinin korunmasıdır [14]. Bu amaçla, PS tedavisinde farklı tedavi seçenekleri tanımlanmıştır. Genel olarak, bu yöntemler punktumun basit bir dilatör ile veya daha invaziv punktal 1-4 Snip punktoplasti (SP), panç punktoplasti cerrahileri ile genişletilmesini; delikli punktum tıkacı ve stentler (Mini-Monoka, Self-retaining bikanaliküler entübasyon seti, FCl Nunchaku silikon tüp, Kaneka Lacriflow silikon set) ile genişletilmiş açıklığın devamının sağlanmasını kapsamaktadır.

Punktum stenozunda başlangıçta kısmi tıkanıklıklarda ve hafif 2. veya 3. derece punktum açıklığı olan hastalarda sadece dilatasyon denenebilir. Ancak, tekrarlayan dilatasyonlar punktum ve kanalikülde iyatrojenik stenoza yol açabilir. Dilatasyon sırasında punktum ve kanalikülün en az travmaya uğraması için künt uçlu dilatörler kullanılmalıdır. Tam tıkanıklık durumunda ve çok dar punktumlarda, dilatasyonun yetersiz olduğu hastalarda invaziv cerrahiler gereklidir.

Cerrahiyi reddeden hastalarda argon lazer ile punktum açıklığının genişletilmesi sınırlı sayıdaki vakada denenmiş, erken dönemde açıklığın devam ettiği bildirilmiştir [30]. Ancak bu uygulama, literatürde popüler olmamıştır. Cerrahiden kaçınan epiforalı olgularda lakrimal beze botilinum toksin enjeksiyonu da etkisi geri dönüşümlü olsa da bir seçenek olarak literatürde yer almıştır [31].
Panç yardımıyla posterior ampullektomi yapılabilir. PS için geliştirilen Reiss punktal panç ile \%92 oranında fonksiyonel başarı bildirilse de yaygın kullanım alanı bulamamıştır [32]. Desme membranı için geliştirilen Kelly panç, daha sonraları kullanılan diğer bir pançtır [33]. Kelly panç ile punktumun kontrollü genişletilmesinin sağlandığı düşünülmekte; etkinin, punktal açıklığa yönelik olmasıyla Riolan kasının zarar görmemesi, daha az kanama ve kanaliküler sistemin dairesel yapısının az hasarlanması bu yöntemin bir avantajı olarak görülmektedir [33].

Snip punktoplasti (SP) kesi sayısına göre literatürde 1-Snip'den 4-Snip'e kadar farklı modifikasyonları ile tanımlanan, en eski ve sık yapılan prosedürlerdendir [34]. 1853'te ilk defa Bowman'ın uyguladığı 1-SP'de punktumdan ampulla ve kanalikülü de içine alan tam kat kesi yapılmaktadır (Resim 6a). Jones ise bu kesiyi sadece ampullayı da içine alan uzunlamasına vertikal tam kat kesi olarak uygulamıştır (Resim 6a). Ancak kesi kenarlarının skarlaşması ve tekrar birleşmeleri, anatominin bozulması cerrahi başarıyı olumsuz etkiler. Kanalikül anatomisinin bozulması dezavantajlarındandır. 2-SP, 1-SP yapılan hastalarda takiplerde yara dudakları yaklaşma eğiliminde ise, kesinin alt kenarından kanaliküle doğru ikinci bir kesi yapılarak uygulanmıştır [19]. Daha yeni bir yayında da bir olguda sütür yardımlı 2-Snip insizyon yapılarak üçgen şeklinde doku çıkarılarak posterior ampullektomi oluşturulduğu bildirilmiştir [35].

3-SP ile posterior ampullektomiyi Graves ve ardından Thomas tanımlamıştır [19]. Klasik üçgen 3-SP'de punktumdan ampullaya doğru vertikal, ardından horizontal insizyon yapılarak oluşturulan üçgen flep 3. insizyon ile eksize edilir (Resim 6b). İnsizyon bir miktar kanalikülün proksimal kısmını da içerir. Geri dönüşsüz bir cerrahi olması ve her zaman sonuç vermemesine rağmen, geniş bir açıklık sağlaması dolayısıyla yüksek fonksiyonel başarı sağlamaktadır.

Dörtgen 3-SP'de klasik üçgen 3-SP'den farklı olarak vertikal kanaliküle iki paralel vertikal kesi yapılır ve oluşan dörtgen flep, tabanından üçüncü kesi ile çıkarılır (Resim 6c). Bu şekilde anatomi ve pompa fonksiyonu daha az bozulmaktadır. Chak ve Irvine [36] dörtgen 3-SP'de \%89,8'lik bir başarı elde etmişler ve üçgen 3-SP ile benzer sonuçlar bildirmişlerdir. Dörtgen 3-SP uygulanan hastalarında Ali ve ark. [37] en az altı ay takip edilen hastalarının \%74,7'sinde semptomların 

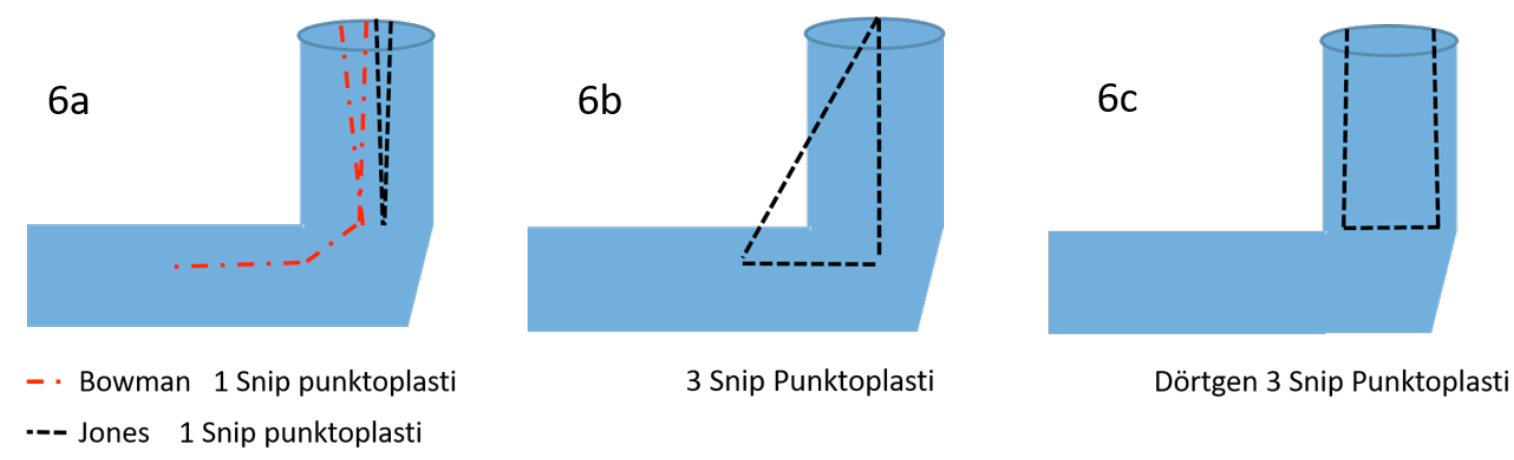

Resim 6. Snip punktoplasti (SP) yöntemleri

6a. Kırmızı kesik çizgi Bowman'ın tarif ettiği 1-SP, siyah kesikli çizgi Jones'un uyguladığı 1-SP yöntemini göstermektedir.

6b. Ampulla bölgesinden bir miktar horizontal kanalikülü de içine alan üç adet kesi ile eksizyonun yapıldığı klasik üçgen 3-SP gösterilmiştir.

6c. Ampullanın vertikal olarak eksizyonu ile sınırlı dörtgen 3-SP'nin şematik tarifi görülmektedir.

tamamen kaybolduğunu ancak \%10,3'ünde ise lakrimal sistem açıklığı sağlanmasına rağmen epiforanın devam ettiğini, \%5,7'sinde de PS'nun tekrarladığını bildirmişlerdir. \%10,3 oranında ise punktum distalindeki obstrüksiyon nedeniyle epiforanın devam ettiği sonucuna varmışlardır.

Dörtgen 3-SP yönteminde flebi kestikten sonra ampullanın posterior duvarına üç adet 10,0 nylon sütür konularak mukozal bütünlük sağlanabilir ve punktal genişlik ve tekrar yara dudaklarının yapışması önlenebilir. Park ve ark. [38] bu yöntemle anatomik restenozu sadece $\% 2,1$ olarak kaydetmişlerdir.

4-SP'de ise dört insizyon ile posteriordan kanalikül proksimalinin de dahil olduğu geniş bir eksizyon yapılır [39]. 4-SP ile altı aylık takiplerinde Kim ve ark. [39] \%93,3'lik fonksiyonel bir başarı bildirmişlerdir. Ağır stenozlu olgularda geniş bir açıklık sağlanması için avantaj olduğu düşünülebilir.

Stenotik bölgenin insizyonlarla ve punç ile genişletilmesinden daha az invaziv yöntem arayışları içinde delikli punktum tıkaçlarının (DPT) kullanılması gelmektedir. DPT'nın görece inaziv olmaması, geri dönüşlü ve kolay uygulanabilir olması bir avantajdir. Illk uygulanılan punktum tıkaçları 0,6 mm çapında silikondur. Ancak açıklığı sekresyonlarla kolayca tıkanabilir ve punktum tıkacına bağlı sekonder granülasyon da gelişebilir [40]. Bu nedenle Polyvinylpyrrolidone (PVP) hidrofilik kaplamalı model geliştirilmiştir ( $\mathrm{FCl}$, Pembroke, $\mathrm{MA})$. Bu, silikondan daha hidrofilik bir yüzeye sahiptir. Konuk ve ark.'na [41] göre PVP kaplamalı DPT ile cerrahi başarı uzun dönemde tatmin edicidir $(\% 84,1)$. DPT'nın başarısını artırmak için implante etmeden önce mitomisin-C uygulaması ile erken dönemde gözyaşı yıkanma zamanının \%90 normalleştiği kaydedilmiştir [42]. Silikon tıkaçların punktum ve kanalikül stenozu geliştirmesi, punktum tıkaçlarının distal lakrimal sistemlere kaçması ve dakriyosistit gelişimi olası problemlerdir [43, 44]. DPT'nın diğer bir sorunu da yerinden erken çıkma ve kaybolmasıdır [41]. DPT, 2-6 ay sonra çıkarılmaktadır [41, 42].

Mini-Monoka® (MM) (FCl Ophthalmics, IssyLes-Moulineaux, Fransa) öncelikle kanalikül laserasyonlarında kullanılmaktadır. Özellikle kanaliküler stenoz ile kombine hastalarda tercih edilebilir. Punktuma oturan düz, genişçe, delikli ağzı, dar bir boyun ve ampullaya oturan genişleyen kısmı ince bir tüp ile devam eder. Kanalikülün boyuna göre yerleştirme öncesi tüp boyu kısaltılır. Kolay uygulanabilirliği, sütür gerekmemesi, düz yüzeyinin punktuma oturarak sabitlenmesi sayesinde kornea irritasyonu yaratmaması ve kanaliküle migrasyon riskinin düşüklüğü bir avantajdır. 1-SP ile beraber uygulandığında \%85'lik bir fonksiyonel başarı gösterilmiştir [14]. Genişleyen kısmının ampullaya oturtma manevrası zor olabilir. Yerleştirmeyi 1-SP kolaylaştırabilir, ancak MM çıkarıldıktan sonra skarlaşma ve restenoz gelişebilir. Sadece punktum dilatasyonu yapıldıktan sonra da MM yerleştirilebilir [45]. Yaklaşık $1-3$ ay sonra MM çıkarıı $[14,46]$. Hussain ve ark. [46] $27 \mathrm{G}$ lakrimal kanül ile lavaj ve $0 / 0$ Bowman probu ile sondalamanın ardından MM yerleştirdikleri ve altı hafta sonra 
çıkardıkları hastalarda erken dönemde \%88'lik bir fonksiyonel başarı bildirmiştir. Planlanandan önce MM'nın erken çıkması, kaybolması ve kanaliküle migrasyon, restenoz MM ile karşılaşılabilecek sorunlardır [14, 46].

Bikanaliküler stentler de PS ve KS'nda kullanılmaktadır. Bu amaçla Nunchaku-style silikon tüp (Kaneka Corporation, Tokyo, Japan; $\mathrm{FCl}$, Paris, France), Self-Retaining Bikanaliküler entübasyon seti (SRBS) ( $\mathrm{FCl}$ Ophthalmics) ve Kaneka Lacriflow CL (Lacriflow) (Kaneka Pharma America, New York, NY) gibi silikon sistemler geliştirilmiştir. Nunchaku tipi silikon tüp ile Mimura ve ark. [47] PS ile KS'unu ayırmadan üst nazolakrimal sistem tıkanıklıklarında uyguladıkları hastalarda bir yıl sonraki takiplerinde \%94,6 gibi yüksek başarı oranları bildirmişlerdir. Lacriflow da Nunchaku silikon tüpün bir varyasyonu olup, benzer şekilde bikanalikülonazal intubasyon sağlayan silikon bir tüptür. KS ve/veya OKS'nun birlikte olduğu PS'nda uygulanabilir [48]. Bikanaliküler yerleştirilen ve lakrimal keseye kadar ilerletilen SRBS de KS ve OKS'nun eşlik ettiği olgularda bir avantaj olabilir. Chalvatzis ve ark. [48] prospektif çalışmalarında 3-SP ile SRBS uygulanan PS'unda altı ay sonraki fonksiyonel başarının daha yüksek olduğunu göstermişlerdir. SRBS uygulamasında da erken dönemde dislokasyon ve tüpün kaybolması görülebilmektedir [49].

PS'nda başarıyı etkileyen faktörlerden biri de PS'nun distalinde de stenoz varlığıdır. Ali ve ark. [37] üçgen 3-SP uyguladıkları hastaların $\% 9,1$ 'inde bu nedenle hiçbir düzelme görmemişlerdir. PS olan olgularda punktum distalinin değerlendirilmesi başarılı bir sonuç elde edilebilmesi için çok önemlidir. Erken dönemde takip ve skatrizasyona dilatasyon uygulaması başarıyı arttırabilir. Fraser ve ark. [50] 3-SP uyguladıkları hastalarda erken dönemde skar gördüklerinde tekrarlayan dilatasyonlar ile bu skarların açıldığını ve başarılarının \%95,5 olduğunu bildirmişlerdir. Başarısız olgularda sekonder 3-SP ile kombine stent uygulamaları başarılı olabilmektedir [36]. Dirençli tekrarlayan PS'larında SP ile stent uygulamaları kombine uygulanabilir.

Sonuç olarak PS, birçok etyolojik nedene bağlı, izole veya daha distal lakrimal drenaj sisteminin stenozu ile kombine olan bir patolojidir. Klinik değerlendirme, seçilecek cerrahi tekniği belirlemede önemlidir. Distal lakrimal drenaj sisteminin bozukluğu başarıyı büyük oranda etkilemektedir. Epiforalı hastalara yaklaşımda PS'nun akılda tutulması, risk faktörlerinin bilinmesi, PS'nda cerrahi sonrası yakın takibin yapılması, semptomatik hastalarda sekonder cerrahi planlanması önemlidir.

Çıkar ilişkisi: Yazar çıkar ilişkisi olmadığını beyan eder.

\section{Kaynaklar}

1. Viso E, RodriguezAres MT, Gude F. Prevalence and associations of external punctal stenosis in a general population in Spain. Cornea 2012;31:1240-1245. https://doi.org/10.1097//CO.0b013e31823f8eca

2. Bukhari A. Prevalence of punctal stenosis among ophthalmology patients. Middle East Afr J Ophthalmol 2009;16:85-87. https://doi.org/10.4103/09749233.53867

3. Mainville N, Jordan DR. Etiology of tearing: a retrospective analysis of referrals to a tertiary care oculoplastics practice. Ophthalmic Plast Reconstr Surg 2011;27:155-157. https://doi.org/10.1097/ IOP.0b013e3181ef728d

4. Ulusoy MO, Atakan M, Kıvanç SA. Prevalence and associated factors of external punctal stenosis among elderly patients in Turkey. Arq Bras Oftalmol 2017;80:296-299. https://doi.org/10.5935/00042749.20170072

5. Takahashi $\mathrm{Y}$, Kakizaki H, Nakano T, Asamoto $\mathrm{K}$, Ichinose A, Iwaki M. Anatomy of the vertical lacrimal canaliculus and lacrimal punctum: a macroscopic study. Ophthal Plast Reconstr Surg 2011;27:384-386. https://doi.org/10.1097//OP.0b013e318219a54b

6. Lipham WJ, Tawfik HA, Dutton JJ. A histologic analysis and three-dimensional reconstruction of the muscle of Riolan. Ophthal Plast Reconstr Surg 2002;18:93-98. https://doi.org/10.1097/00002341-200203000-00002

7. Patel S, Wallace I. Tear meniscus height, lower punctum lacrimale, and the tear lipid layer in normal aging. Optom Vis Sci 2006;83:731-739. https://doi. org/10.1097/01.opx.0000236810.17338.cf

8. Carter KD, Nelson CC, Martonyi CL. Size variation of the lacrimal punctum in adults. Ophthal Plast Reconstr Surg 1988;4:231-233.https://doi.org/10.1097/00002341198804040-00006

9. Yoon KC, Jeong SK, Park YG. Study of lacrimal punctal size in normal adults. J Korean Ophthalmol Soc 1997;38:1916-1920.

10. Kashkouli MB, Beigi B, Murthy R, Astbury N. Acquired external punctal stenosis: etiology and associated findings. Am J Ophthalmol 2003;136:1079-1084. https://doi.org/10.1016/s0002-9394(03)00664-0 
11. Offutt WN, Cowen DE. Stenotic puncta: microsurgical punctoplasty. Ophthalm Plast Reconstr Surg 1993;9:201-205. https://doi.org/10.1097/00002341199309000-00006

12. Kristan RW. Treatment of lacrimal punctal stenosis with a one-snip canaliculotomy and temporary punctal plugs. Arch Ophthalmol 1988;106:878-879. https://doi. org/10.1001/archopht.1988.01060140020006

13. Port AD, Chen YT, Lelli GJ Jr. Histopathologic changes in punctal stenosis. Ophthalmic Plast Reconstr Surg 2013;29:201-204. https://doi.org/10.1097/ IOP.0b013e31828a92b0

14. Kashkouli MB, Beigi B, Astbury N. Acquired external punctal stenosis: surgical management and longterm follow-up. Orbit 2005;24:73-78. https://doi. org/10.1080/01676830490916055

15. O'Donnell FE. Medial ectropion: association with lower lacrimal obstruction and combined management. Ophthalmic Surg 1986;17:573-576.

16. Satchi K, McNab AA. Conjunctival cicatrizing disease presenting with lacrimal obstruction. Orbit 2016;35:321323. https://doi.org/10.1080/01676830.2016.1193539

17. Kamoi M, Ogawa Y, Dogru M, etal. Spontaneous lacrimal punctal occlusion associated with ocular chronic graftversus-host disease. Curr Eye Res 2007;32:837-842. https://doi.org/10.1080/02713680701586409

18. Sotozono C, Ueta M, Yokoi N. Severe dry eye with combined mechanisms is involved in the ocular sequelae of SJS/TEN at the chronic stage. Invest Ophthalmol Vis Sci 2018;59:80-86. https://doi. org/10.1167/iovs.18-24019

19. Caesar RH, McNab AA. A brief history of punctoplasty: the 3-snip revisited. Eye (Lond) 2005;19:16-18. https:// doi.org/10.1038/sj.eye.6701415

20. Rumelt S, Pe'er J, Rubin PA. The clinicopathological spectrum of benign peripunctal tumours. Graefes Arch Clin Exp Ophthalmol 2005;243:113-119. https://doi. org/10.1007/s00417-004-0907-x

21. McNab AA. Lacrimal canalicular obstruction associated with topical ocular medication. Aust N Z J Ophthalmol 1998;26:219-223. https://doi. org/10.1111/j.1442-9071.1998.tb01315.x

22. Kopp ED, Seregard S. Epiphora as a side effect of topical mitomycin C. Br J Ophthalmol 2004;88:14221424. https://doi.org/10.1136/bjo.2004.048033

23. Ma'luf RN, Hamush NG, Awwad ST, Noureddin $\mathrm{BN}$. Mitomycin $\mathrm{C}$ as adjunct therapy in correcting punctal stenosis. Ophthalmic Plast Reconstr Surg 2002;18:285-288. https://doi.org/10.1097/00002341200207000-00010

24. Kashkouli MB, Parvaresh MM, Mirzajani H, Astaraki A, Falavarjani KG, Ahadian A. Intraoperative mitomycin $C$ use during filtration surgery and lacrimal drainage system obstruction. Am J Ophthalmol 2009;147:453457. https://doi.org/10.1016/j.ajo.2008.08.037
25. Brink HM, Beex LV. Punctal and canalicular stenosis associated with systemic fluorouracil therapy. Report of five cases and review of the literature. Doc Ophthalmol 1995;90:1-6. https://doi.org/10.1007/BF01203288

26. Skolnick CA, Doughman DJ. Erosive conjunctivitis and punctal stenosis secondary to docetaxel (taxotere). Eye Contact Lens 2003;29:134-135. https://doi. org/10.1097/01.ICL.0000062464.79558.5A

27. Morgenstern KE, Vadysirisack DD, Zhang $Z$, et al. Expression of sodium iodide symporter in the lacrimal drainage system: implication for the mechanism underlying nasolacrimal duct obstruction inl ${ }^{131}$-treated patients. Ophthalmic Plast Reconstr Surg 2005;21:337-344. https://doi.org/10.1097/01. iop.0000179369.75569.a8

28. Kornhauser T, Segal A, Walter E, Lifshitz T, Hartstein $\mathrm{M}$, Tsumi E. Idiopathic edematous punctal stenosis with chronic epiphora: preponderance in young women. Int Ophthalmol 2019;39:1981-1986. https:// doi.org/10.1007/s10792-018-1031-y

29. Sibley D, Norris JH, Malhotra R. Management and outcomes of patients with epiphora referred to a specialist ophthalmic plastic unit. Clin Exp Ophthalmol 2013;41:231-238. https://doi.org/10.1111/j.14429071.2012.02866.x

30. Awan KJ. Laser punctoplasty for the treatment of punctal stenosis. Am J Ophthalmol 1985;100:341-342. https://doi.org/10.1016/0002-9394(85)90814-1

31. Singh S, Nair AG, Alam MS, Mukherjee B. Outcomes of lacrimal gland injection of botulinum toxin in functional versus nonfunctional epiphora. Oman J Ophthalmol 2019;12:104-107. https://doi.org/10.4103/ ojo.OJO_52_2018

32. Edelstein J, Reiss G. The wedge punctoplasty for treatment of punctal stenosis. Ophthalmic Surg 1992;23:818-821.

33. Priel A, Rosner M, Ben Simon G, et al. The clinical and histopathological characteristics of Kelly punch punctoplasty. Eye (Lond) 2020. https://doi.org/10.1038/ s41433-020-0813-4

34. Hurwitz JJ. Disease of the punctum. In: Hurwitz JJ (ed), The lacrimal system. Lippincott-Raven: Philadelphia, PA, USA, 1996:149-153.

35. Sachdev A, Sagili SR. Suture-assisted punctoplasty. Digit J Ophthalmol 2017;23:60-62. https://doi. org/10.5693/djo.01.2017.01.001

36. Chak M, Irvine F. Rectangular 3-snip punctoplasty outcomes: preservation of the lacrimal pump in punctoplasty surgery. Ophthalmic Plast Reconstr Surg 2009;25:134-135. https://doi.org/10.1097/ IOP.0b013e3181994062 
37. Ali MJ, Ayyar A, Naik MN. Outcomes of rectangular 3-snip punctoplasty in acquired punctal stenosis: is there a need to be minimally invasive? Eye(Lond) 2015;29:515-518. https://doi.org/10.1038/ eye.2014.342

38. Park SJ, Noh JH, Park KB, Jang SY, Lee JW. A novel surgical technique for punctal stenosis: placement of three interrupted sutures after rectangular three-snip punctoplasty. BMC Ophthalmol 2018;18:70. https://doi. org/10.1186/s12886-018-0733-2

39. Kim SE, Lee SJ, Lee SY, Yoon JS. Outcomes of 4-snip punctoplasty for severe punctal stenosis: measurement of tear meniscus height by optical coherence tomography. Am J Ophthalmol 2012;153:769-773. https://doi.org/10.1016/j.ajo.2011.09.026

40. Ababneh $\mathrm{OH}$, Msallam MM. Bilateral simultaneous pyogenic granuloma after perforated punctal plug insertion. Ophthalmic Plast Reconstr Surg 2014;30:113115. https://doi.org/10.1097//OP.0b013e3182a5ba6b

41. Konuk O, Urgancioglu B, Unal M. Long-term success rate of perforated punctal plugs in the management of acquired punctal stenosis. Ophthalmic Plast Reconstr Surg 2008;24:399-402. https://doi.org/10.1097/ IOP.0b013e318185a9ca

42. Abd El Ghafar AS, El Kannishy AM, Elwan MM, Sabry D, Kishk HM, Elhefney EM. Perforated punctal plugs with adjuvant use of mitomycin- $C$ in management of acquired external punctal stenosis grades 0 and 1. Can J Ophthalmol 2017;52:606-610. https://doi. org/10.1016/j.jcjo.2017.06.009

43. Boldin I, Klein A, Haller Schober EM, Horwath Winter J. Long-term follow-up of punctal and proximal canalicular stenoses after silicone punctal plug treatment in dry eye patients. Am J Ophthalmol 2008;146:968-972. https://doi.org/10.1016/j.ajo.2008.06.028

44. Horwath Winter J, Thaci A, GruberA, Boldin I. Long-term retention rates and complications of silicone punctal plugs in dry eye. Am J Ophthalmol 2007;144:441-444. https://doi.org/10.1016/j.ajo.2007.05.019

45. Mathew RG, Olver JM. Mini-monoka made easy: a simple technique for mini-monoka insertion in acquired punctal stenosis. Ophthalmic Plast Reconstr Surg 2011;27:293-294. https://doi.org/10.1097/ IOP.0b013e31820ccfaf

46. Hussain RN, Kanani H, McMullan T. Use of minimonoka stents for punctal/canalicular stenosis. $\mathrm{Br} \mathrm{J}$ Ophthalmol 2012;96:671-673. https://doi.org/10.1136/ bjophthalmol-2011-300670

47. Mimura M, Ueki M, Oku H, Sato B, Ikeda T. Indications for and effects of Nunchaku-style silicone tube intubation for primary acquired lacrimal drainage obstruction. Jpn J Ophthalmol 2015;59:266-272. https://doi.org/10.1007/s10384-015-0381-5
48. DeParis SW, Hougen CJ, Rajaii F, Mahoney NR. Bicanalicular intubation with the kaneka lacriflow for proximal lacrimal drainage system stenosis. Clin Ophthalmol 2020;14:915-920. https://doi.org/10.2147/ OPTH.S248423

49. Chalvatzis NT, Tzamalis AK, Mavrikakis I, Tsinopoulos I, Dimitrakos S. Self-retaining bicanaliculus stents as an adjunct to 3-snip punctoplasty in management of upper lacrimal duct stenosis: a comparison to standard 3-snip procedure. Ophthalmic Plast Reconstr Surg 2013;29:123-127. https://doi.org/10.1097/ IOP.0b013e31827f5a10

50. Fraser CE, Petrakos P, Lelli GJ Jr. Adjunctive redilation for early cicatrization after punctoplasty. Orbit 2012;31:313-315. https://doi.org/10.3109/01676830.2 012.681751 